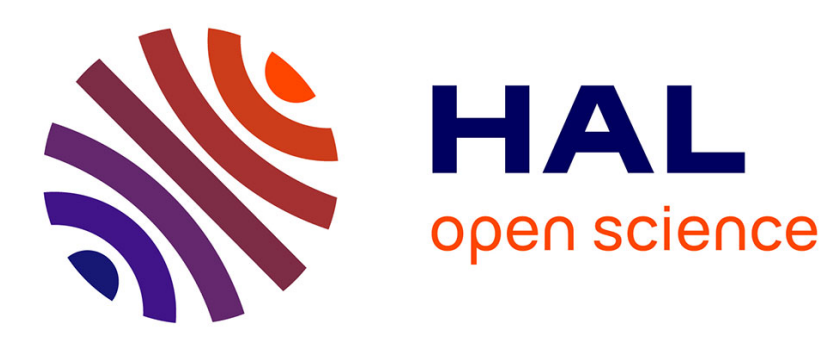

\title{
La perception des attentats du 11 septembre dans le monde arabe et musulman
}

\author{
Lahouari Addi
}

\section{To cite this version:}

Lahouari Addi. La perception des attentats du 11 septembre dans le monde arabe et musulman. Confluences Méditerranée , 2001, 40, pp.165-169. halshs-00398867

\section{HAL Id: halshs-00398867 https://shs.hal.science/halshs-00398867}

Submitted on 25 Jun 2009

HAL is a multi-disciplinary open access archive for the deposit and dissemination of scientific research documents, whether they are published or not. The documents may come from teaching and research institutions in France or abroad, or from public or private research centers.
L'archive ouverte pluridisciplinaire $\mathbf{H A L}$, est destinée au dépôt et à la diffusion de documents scientifiques de niveau recherche, publiés ou non, émanant des établissements d'enseignement et de recherche français ou étrangers, des laboratoires publics ou privés. 
La perception des attentats du 11 septembre dans le monde arabe et musulman

Lahouari Addi

Professeur de sociologie à l'IEP de Lyon et chercheur au CERIEP et au GREMMO

Confluences Méditerranée - º 40 Hiver 2001-2002 - pp 165 -169

Texte intégral

Il a été maintes fois souligné qu'il y a désormais un avant et un après 11 septembre 2001, tant les attentats de New York et de Washington sont lourds de conséquences pour les relations internationales. Le monde bipolaire d'avant la rivalité Est-Ouest n'existe plus, mais la chute du Mur de Berlin n'a pas effacé pour autant les antagonismes des rapports mondiaux et les ressentiments à l'égard de l'hégémonie occidentale sur les plans économique et culturel. La fracture Nord-Sud, perçue différemment par les uns et les autres, n'a jamais semblé aussi profonde qu'à l'heure de la mondialisation qui accroît son caractère insupportable pour ceux qui sont en bas de l'échelle.

Ceci engendre des frustrations et des ressentiments à l'égard de ceux dont l'opulence s'étale dans les séries télévisées de Hollywood regardées dans les favellas brésiliennes et les bidonvilles du Caire et d'Islamabad. A l'inégalité vécue quotidiennement à travers la télévision, s'ajoute le sentiment d'injustice vécu par les centaines de millions de musulmans que révolte le soutien américain inconditionnel à Israël opprimant les Palestiniens.

"Mais pourquoi nous haïssent-ils tant?"

se demandait naïvement G.W. Bush dans un de ses discours, déclarant que les Américains sont pour tant bons. Ceci illustre le décalage de l'élite américaine par rapport à la perception de son pays et de sa responsabilité, directe ou indirecte, dans les conditions économiques et politiques de pays situés en Amérique latine, en Afrique et en Asie. La domination coloniale a pris fin dans les années 1950 et 1960 mais les inégalités qui la caractérisent se sont maintenues et se sont même aggravées pour certains pays. Les anciennes puissances coloniales, la Grande-Bretagne et la France, ont été supplantées par les USA qui pourtant, pour des raisons propres à leur histoire, n'ont pas eu de colonies. Mais l'héritage colonial de ces deux anciennes puissances semble aujourd'hui assumé par les USA qui, volontairement ou non, confortent les logiques inégalitaires de l'ordre mondial né de l'expansion européenne du XIXe siècle.

Cumulant les puissances financières, technologiques et militaires, les Américains n'ont pas conscience que leur pays est devenu en quelques décennies le gendarme de l'ordre mondial néo-colonial intégrant les élites dirigeantes locales qui leur servent de relais, comme si les gouvernants et les élites sociales étaient solidaires des USA contre les intérêts de leurs populations. Nous sommes loin du tiers-mondisme des années 1950 et 1960 porté par Nehru, Tito, Nasser et Boumédiène qui tenaient des discours hostiles à l'hégémonisme américain accusé d'être la cause du sous-développement économique et social de régions entières de la planète. Il n'y a aujourd'hui que Cuba qui continue vaillamment de tenir ce discours, lâché depuis longtemps par l'Algérie, l'Egypte, le Vietnam... Faute de l'avoir défait, les gouvernements du Tiers Monde cherchent à tirer profit de cet hégémonisme dont ils se sont accommodés au fil des ans.

Les USA dominent en effet les principales institutions internationales (ONU, FMI, Banque Mondiale...) et sont les leaders de la culture mondiale à travers le cinéma, la musique et la télévision. L'ordre mondial à la tête duquel ils régnent est une structure hiérarchique d'intérêts inégaux mais solidaires, s'articulant les uns aux autres. Les élites de tous les pays sont quotidiennement soucieuses de l'état de l'économie américaine et de la valeur du dollar, car une récession aux Etats-Unis affecte directement les aides financières aux pays et les capitaux détournés et placés en Bourse où ils fructifient sous forme d'actions. Les conseillers financiers des dirigeants du Tiers Monde ont les yeux 
constamment rivés sur les variations du Dow Jones, dont les caprices peuvent enrichir ou ruiner les détenteurs de portefeuilles boursiers. C'est ainsi que l'évolution de l'indice Dow Jones est mieux suivie que celle du taux de chômage local que rappellent des émeutes périodiques réprimées violemment.

L'intégration des gouvernements locaux dans la structure internationale dominée par les USA donne à cette domination des mécanismes efficaces de reproduction qui rendent inutile, à quelques exceptions près, l'intervention militaire directe. Ne reposant sur aucune discrimination ni raciale ni ethnique, l'ordre mondial, dont les USA sont le gendarme, a toutes les apparences de l'égalité à laquelle peut prétendre n'importe quel individu pourvu de ressources et acceptant les critères de la compétition, sauf que, pour entrer dans celle-ci, il faut avoir les moyens que seuls fournissent de gros capitaux et la maîtrise de la technologie. La mondialisation est ainsi un phénomène de mise en place d'une hiérarchie économique et sociale, au-delà des frontières nationales qu'ignorent les flux de capitaux et d'informations sur les évolutions et les tendances des différents secteurs d'activités. La hiérarchie n'est plus nationale ; elle est désormais internationale.

L'un des effets de cette nouvelle situation est que l'Etat n'est plus le seul acteur des relations internationales comme par le passé. Les individus interviennent dans le champ mondial sous des formes institutionnelles (ONG)ou non institutionnelles (réseaux terroristes clandestins) échappant à la tutelle de contrôle des Etats. La conséquence est que les conflits comme celui du Proche-Orient ne sont plus l'affaire exclusive des Etats. Les gouvernements des pays musulmans s'inquiètent de l'évolution de la confrontation sur le terrain entre l'armée israélienne et les jeunes Palestiniens car à tout moment des manifestations incontrôlées peuvent éclater pour dénoncer leur modération ou leur incapacité à aider les Palestiniens. Il est vrai que la Palestine devient un abcès de fixation du mécontentement interne qui ne trouve aucun canal légal d'expression.

L'exemple de l'Egypte ou du Pakistan, pays musulmans importants du point de vue de la démographie, est illustratif de ce point de vue.

Pris en tenaille par le mécontentement de la rue et les pressions américaines qui exercent le chantage de l'aide financière, les gouvernements

louvoient dans un sens et dans un autre pour ne pas rompre avec la population ni se priver de l'aide américaine nécessaire pour combler des déficits budgétaires déstabilisants. Dans ce cas, les élites dirigeantes arabes ou musulmanes, soumises à l'ordre mondial dont elle sont désormais partie prenante, ne peuvent combler le fossé qui les sépare de leurs opinions publiques à propos du conflit isarélo-palestinien. Des organisations clandestines vont alors se former pour exprimer de façon violente la désapprobation du soutien américain à Israël. Individu privé, Oussama Ben Laden n'aurait jamais eu les forces dont il a disposé si des millions de musulmans n'étaient pas convaincus de la volonté des Américains d'humilier l'islam en encourageant Israël à opprimer les Palestiniens.

De là découlent les réactions des opinions arabes et musulmanes aux attentats du 11 septembre, réactions mitigées et ambiguës à plus d'un titre. D'un côté, il y a la condamnation d'un acte ayant causé la mort de milliers de personnes innocentes; de l'autre, il y a la fierté que des musulmans soient capables de se défendre. Aussi bien dans la presse que dans les conversations privées, deux positions différentes, voire contradictoires, sont mises en avant. L'une consiste à dire que les attentats du 11 septembre, de par leur cruauté et leur inhumanité, ne peuvent être que l'oeuvre des services secrets israéliens qui les ont organisés pour discréditer la cause palestinienne. De nombreuses rumeurs ont en effet circulé sur différents sites internet pointant du doigt les Israéliens, dont certains auraient même été arrêtés par le FBI. La plus persistante a été celle des 4000 employés du World Trade Center d'origine juive qui auraient été informés à l'avance par les services de l'Etat hébreu de ne pas se rendre au travail le 11 septembre. Ils auraient été ainsi épargnés par leurs coreligionnaires responsables des attentats. Cette même position insiste sur le fait que les accusations portées contre Oussama Ben Laden ne reposent sur aucune preuve tangible et que sa désignation comme coupable participe de l'hostilité qu'auraient toujours eue les Etats-Unis à l'égard des musulmans.

La seconde position, revendiquant les attentats, présente Ben Laden comme le défenseur de l'islam bafoué. Il y apparaît comme le justicier et le rebelle capable d'organiser des opérations de représailles avec une précision militaire. Il rappelle le héros musulman portant des coups mortels à l'adversaire, en l'occurrence les USA, obligés à l'avenir de tenir compte des réactions des musulmans dans le Proche-Orient. Certains n'hésitent pas à revendiquer ses actions avec fierté, à exhiber son portrait et à écrire son nom sur les murs, nom qui revêt à lui seul une signification antiaméricaine tranchée. Revendication assumée publiquement ou non et rumeur indiquent l'état d'esprit de la rue dans 
les pays musulmans où l'antiaméricanisme des masses met en difficulté les positions modérées des dirigeants, dont le seul souci est de durer avec l'appui encombrant mais néanmoins indispensable des pays occidentaux.

Il est symptomatique que cette position contradictoire présentant simultanément l'islam comme religion de paix et Oussama Ben Laden comme le héros guerrier et vengeur soit si largement répandue dans les opinions musulmanes, au-delà des courants islamistes qui proclament que les attentats du 11 septembre sont une sanction divine et un avertissement à tous les ennemis de l'islam. Cette contradiction ne renvoie pas à un double discours ni à la divergence des opinions dans les rangs des musulmans. Elle exprime en fait leur désir d'être considérés comme pacifiques et en même temps capables de déchaîner une violence dissuasive. Il y a simultanément le rejet du terrorisme aveugle de Ben Laden et l'affirmation que l'islam produira des Ben Laden s'il est opprimé, et ce à l'adresse de ceux qui soutiennent la politique israélienne à l'égard des Palestiniens.

Les Etats-Unis sous-estiment l'impact sur les opinions musulmanes de leur soutien massif à Israël sur les plans militaire, financier et diplomatique. Mais ce que les opinions musulmanes ne savent pas, c'est que ce soutien provient moins de l'hostilité des Américains à l'égard de l'islam que de l'activisme du lobby pro-israélien très efficace, au point qu'il décide de la ligne à suivre dans le conflit du Proche-Orient. Les relations internationales ne sont pas indépendantes des structures des champs politiques nationaux, dans la mesure où, aux USA, des Américains alignent la position de leur pays sur celle d'un pays étranger - Israël - en conflit avec les Palestiniens dont sont solidaires tous les musulmans de la planète en raison de la dimension symbolique de Jérusalem. Sans en être conscients, les USA sont de facto

en guerre avec les musulmans, et c'est ce que ne semble pas comprendre G.W. Bush, convaincu que lui et ses compatriotes sont bons, autant que puisse l'être le genre humain. 